\title{
Tsunami earthquakes possibly widespread manifestations of frictional conditional stability
}

\author{
S. L. Bilek \\ Department of Geological Sciences, University of Michigan, Ann Arbor, MI, USA
}

T. Lay

Institute of Geophysics and Planetary Physics and Earth Sciences Department, University of California, Santa Cruz, Santa Cruz, CA, USA

Received 26 March 2002; revised 20 May 2002; accepted 3 June 2002; published 20 July 2002.

[1] Tsunami earthquakes, shallow events that produce larger tsunamis than expected given their surface wave magnitudes $\left(\mathrm{M}_{s}\right)$, typically have long durations and a source spectrum depleted in short period energy. Seven cases of underthrusting tsunami earthquakes provide information on the rupture processes, but little constraint on geographic distribution or frequency. We compare their rupture characteristics with smaller magnitude earthquakes on circum-Pacific interplate thrust faults. Comparable moment release time histories are found for large tsunami earthquakes and for many smaller shallow subduction zone earthquakes, with significantly longer durations and additional source complexity than for events deeper than $15 \mathrm{~km}$. Thus, very shallow interplate earthquake ruptures are scale invariant, with variable frictional properties on the plate interface controlling the depth dependent rupture process. Widespread occurrence of small shallow interplate earthquakes with long durations suggests that many subduction faults have frictional properties that may enable large tsunamigenerating earthquakes to occur; fortunately, large shallow ruptures are infrequent. INDEX TERMS: 7215 Seismology: Earthquake parameters; 7230 Seismology: Seismicity and seismotectonics; 8123 Tectonophysics: Dynamics, seismotectonics

\section{Introduction}

[2] There have only been a handful of documented tsunami earthquakes (Table 1), and no unique feature of subduction environments has been linked to their occurrence, complicating assessment of hazard posed by such earthquakes. Are these earthquakes anomalous results of very rare special circumstances, or are they simply an infrequent manifestation of widespread common conditions? Most explanations for strong tsunami excitation invoke earthquake rupture influenced by sediments or weaker material on the shallowest portion of the subduction zone plate interface [Kanamori, 1972; Satake and Tanioka, 1999; Tanioka and Satake, 1996; Pelayo and Wiens, 1992; Okal, 1988; Kanamori and Kikuchi, 1993; Satake, 1994; Velasco et al., 1994; Polet and Kanamori, 2000].

[3] However, tsunami earthquakes have occurred in regions with large sedimentary wedges, no sedimentary wedge, diverse subducting plate bathymetry, and a wide range of convergence rate and subducting plate age. Analysis

Copyright 2002 by the American Geophysical Union. 0094-8276/02/2002GL015215 of the numerous smaller shallow earthquakes in subduction zones may provide key information about the spatial distribution of future tsunami earthquakes even though small events are not intrinsically tsunamigenic because they produce minor ocean floor displacement. Previous studies indicate that moderate size subduction zone thrust earthquakes in the shallowest $10-15 \mathrm{~km}$ of the fault zone have significantly longer rupture durations on average than deeper interplate earthquakes [Bilek and Lay, 1999, 2000], providing a basis for comparison with the long duration large tsunami earthquakes.

\section{Data}

[4] We analyze 525 earthquakes in 14 circum-Pacific subduction zones with seismic moment magnitudes $\left(\mathrm{M}_{w}\right)$ of 5.0-7.5 and focal mechanisms and locations consistent with underthrusting on the major interplate faults. Event criteria include appropriateness of focal mechanism, location, and data quality. We estimate each events source duration from its source time function (the time history of seismic moment release during faulting) determined by multistation deconvolution of global broadband $\mathrm{P}$ waves [Ruff and Kanamori, 1983; Ruff, 1989; Tichelaar and Ruff, 1991; Ruff and Miller, 1994]. Durations are measured from the source time functions for each earthquake, and scaled to remove the effect of seismic moment. Each duration estimate is divided by the cube root of the associated earthquake $\mathrm{M}_{o}$ from the Harvard CMT catalog, normalized to a $\mathrm{M}_{w}=6.0$ event $\left(\mathrm{M}_{o}=1.16 \times 10^{18} \mathrm{Nm}\right)$ [Kanamori and Anderson, 1975; Houston et al., 1998; Campus and Das, 2000]. Error bars reflect uncertainties in measuring durations from source time functions and the depth range that minimizes deconvolution errors. Scaled earthquake source duration dependence on source depth is shown in Figure 1 for the entire circum-Pacific dataset as well as for specific subduction zones where large tsunami earthquakes have occurred historically. There is a general trend of decreasing source duration with increasing depth down to about $15 \mathrm{~km}$, with average durations of the shallowest earthquakes about 2 to 3 times longer than typical deeper interplate events.

\section{Comparison with Tsunami Earthquake Source Parameters}

[5] We compare this dataset with source parameter estimates for well studied tsunami earthquakes. Table 1 lists 
Table 1. Source Parameters for Tsunami Earthquakes

\begin{tabular}{|c|c|c|c|c|c|c|}
\hline Region & Date & $\mathrm{M}_{w}$ & $\mathrm{M}_{o}(\mathrm{Nm})$ & Depth $(\mathrm{km})$ & Duration (s) & NSD (s) \\
\hline Japan & $1896 / 06 / 151,2$ & 8.0 & $1.2 \mathrm{e} 21$ & $0-10$ & 100 & 9.9 \\
\hline Alaska & 1946/04/01 3 & 8.2 & $2.3 \mathrm{e} 21$ & $0-10$ & $100-150$ & 10.0 \\
\hline \multirow{2}{*}{ Peru } & $1960 / 11 / 204$ & 7.6 & $3.4 \mathrm{e} 20$ & 9 & 125 & 19.5 \\
\hline & $1996 / 02 / 215$ & 7.5 & $1.9 \mathrm{e} 20$ & $7-10$ & 50 & 9.2 \\
\hline \multirow[t]{2}{*}{ Kuriles } & $1963 / 10 / 206$ & 7.8 & $6.0 \mathrm{e} 20$ & 9 & 85 & 10.5 \\
\hline & $1975 / 06 / 106$ & 7.5 & $2.0 \mathrm{e} 20$ & 5 & $80-100$ & 16.1 \\
\hline Nicaragua & $1992 / 09 / 027$ & 7.7 & $4.2 \mathrm{e} 20$ & $0-10$ & 125 & 17.5 \\
\hline
\end{tabular}

Data references: 1. Kanamori [1972], 2. Tanioka and Satake [1996], 3. Johnson and Satake [1997], 4. Pelayo and Wiens [1990], 5. Ihmlé et al. [1998], 6. Pelayo and Wiens [1992], 7. Ihmlé [1996].

source parameters for the seven historic tsunami earthquakes believed to be associated with conventional faulting rather than submarine slumps. These earthquakes are larger magnitude $\left(\mathrm{M}_{w}\right.$ 7.5-8.2) than the earthquakes in our circum-Pacific dataset, but have similar fault geometry (shallow underthrusting along the plate interface). We omit the $1994 \mathrm{M}_{w}$ 7.6 Java earthquake because we lack small underthrusting shallow events in that region for comparison. There is also some question over its classification as a tsunami earthquake; it did produce a large tsunami and was initially identified as a tsunami earthquake [Newman and Okal, 1998; Polet and Kanamori, 2000]. However, Abercrombie et al. [2001] suggest this earthquake did not have a slow shallow rupture as observed for the other tsunami earthquakes and that the tsunami run-up heights were within uncertainities in model predictions.

[6] We scale the source durations of the tsunami earthquakes using the same procedure as used for our other events. Figure 1 shows that the tsunami earthquake parameters overlie the general trend of the smaller magnitude shallow underthrusting earthquake dataset. This suggests that tsunami earthquakes are not anomalous relative to other very shallow events, and that there is a strong depth dependence affecting all interplate thrust events.

[7] The characteristics of the source time histories, or moment rate functions, for the 2 subsets of subduction zone earthquakes are compared in Figure 2. Here we present source time functions for 5 shallow $(0-10 \mathrm{~km})$ long duration earthquakes for each region, average time functions for all shallow $(0-10 \mathrm{~km})$ events in each region, and scaled versions of the available source time functions for the tsunami earthquakes. There is substantial variation in the source time functions, so the average time functions are shown as a conservative representation. The seismic moment and duration of the time functions are scaled to a reference seismic moment. The timescales are scaled by $\mathrm{M}_{o}^{1 / 3}$ and the moment rate axes are scaled by $\mathrm{M}_{o}^{2 / 3}$ in order to maintain the relationship between moment and area under each time function. The source functions are scaled such that the area beneath each curve is equal to $1.16 \times$ $10^{18} \mathrm{Nm}$, the moment of the reference event $\left(\mathrm{M}_{w}=6.0\right)$. These time functions, digitized from sources in Table 1, are scaled using the same normalization procedure.

[8] The tsunami earthquake time functions are similar in duration and shape to the shallow earthquake time functions, although some tsunami earthquakes have initial phases with weak radiation that shift the primary energy release in time. The small events in our dataset may also have had similar weak precursory energy that were at the noise level of our data. A stacked source function for deeper events in all 14 subduction zones is included to represent typical deeper interplate thrust events. The shallow earthquake time functions demonstrate the relatively long durations of the shallowest earthquakes, as well as the additional complexity not observed in the deeper earthquake time functions.

[9] There is substantial uncertainty in the tsunami earthquake time functions for the older earthquakes. The 1946 Aleutian earthquake time function is based on inversion of older seismograms than used in more recent analysis. In addition, uncertainties in the focal mechanism and contribution from a possible submarine slump introduce additional
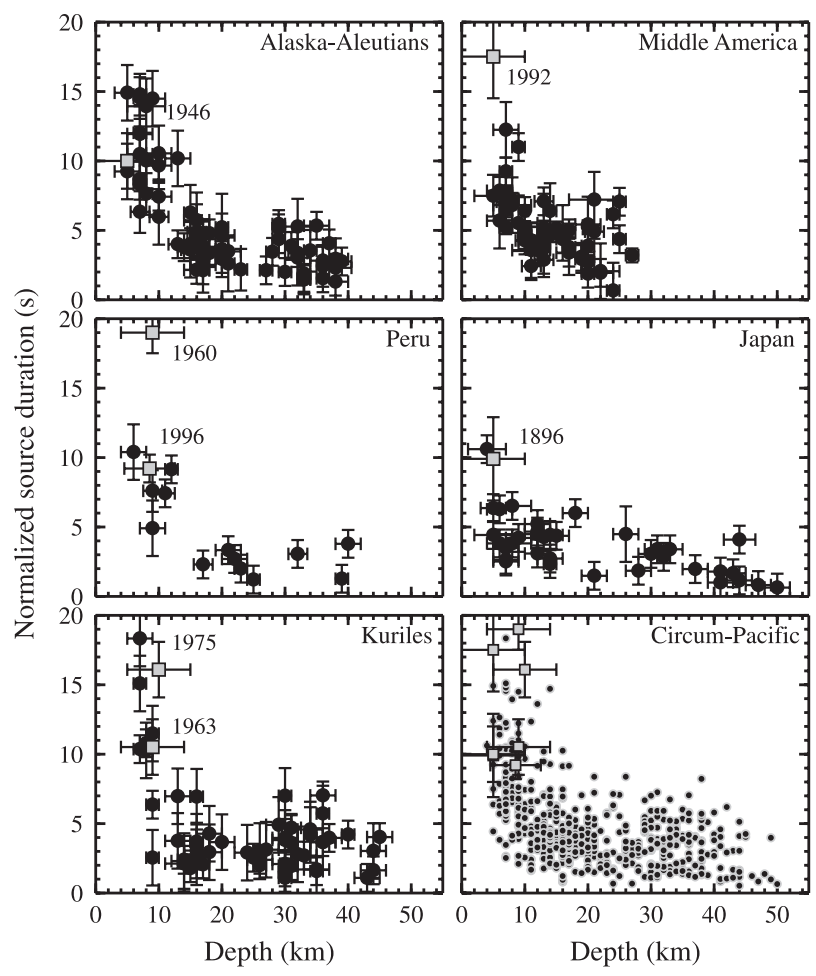

Figure 1. Scaled source duration as a function of depth for shallow underthrusting subduction zone earthquakes. Five panels showevents in individual (labeled) subduction zones with documented tsunami earthquakes, while the panel labeled Circum-Pacific shows source parameter estimates from 525 moderate size $\left(\mathrm{M}_{w}\right.$ 5.0-7.5) earthquakes from around the circum-Pacific (circles). Mexican and Central American earthquakes are combined for the Middle America dataset. Squares are source parameters for large tsunami earthquakes. Durations and depths of the large tsunami earthquakes are taken from the literature (Table 1); durations are scaled by the same procedure. 

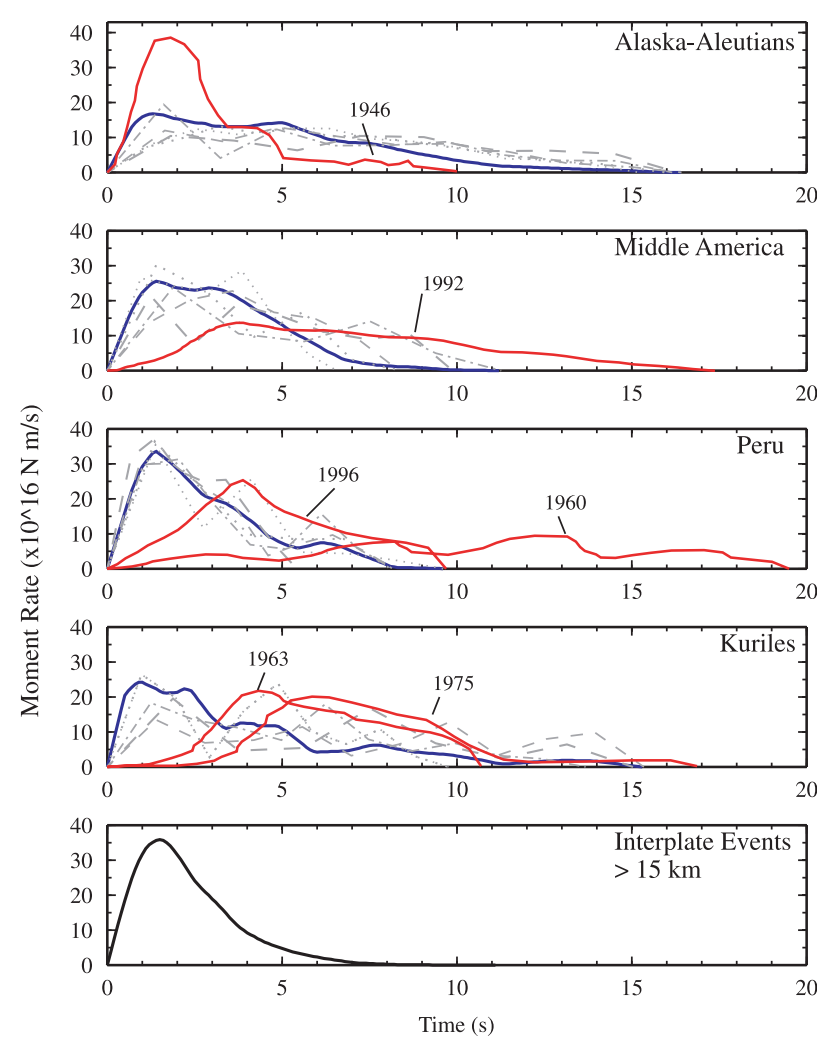

Figure 2. Source time function comparison. Broken lines correspond to source time functions for moderate size earthquakes with depth $0-10 \mathrm{~km}$. Average time functions for all shallow $(0-10 \mathrm{~km})$ earthquakes shown for each region (gray solid line). Black solid lines show scaled source time functions for the six tsunami earthquakes for which seismic models are available. For comparison, average time function for all events greater than $15 \mathrm{~km}$ depth is shown (bottom panel).

complications for this tsunami earthquake that are unresolved with the data available. In general, however, the tsunami earthquake time functions look similar to the smaller magnitude shallow thrust earthquake time functions in both overall shape, complexity, and duration. There is no dramatic effect of total event size, with shallow events of all size being, on average, longer duration and more complex than events deeper than about $15 \mathrm{~km}$. There are exceptions amongst moderate size shallow events, some of which are not distinctive from deeper earthquakes, but the average behavior appears to be common. The variations in source functions between large tsunami earthquakes are as substantial as those amongst small shallow events. Variable source complexity is typical of earthquakes, and we would not expect all source functions to be identical as seen in the individual earthquake time functions shown in Figure 2.

\section{Discussion and Conclusions}

[10] Figure 3 shows a schematic of the subduction plate interface zone that provides a mechanism affecting rupture of shallow earthquakes in contrast to deeper events. Scholz [1990, 1998] describes three possible stability regimes for the typical subduction zone. These include a stable zone where seismic slip cannot be supported and aseismic creep relaxes all strains, an unstable zone where episodic seismic slip occurs, and a conditionally stable zone in between the stable and unstable zones where slip is generally stable, but can be abrupt if it experiences significant loading from a nearby earthquake. This conditionally stable regime may include sedimentary materials with lower strength or lower rigidity than found in the unstable zone; rupture through this region would likely involve slow rupture velocity, resulting in an earthquake with long duration. Previous discussion of these shallow subduction zone earthquakes related observed long durations with low rigidity materials in the source region [Bilek and Lay, 1999]. It appears from our observations of intermediate size earthquakes that this holds equally for magnitude 6.0 events as for magnitude 8.0 events. The most unusual attribute of the shallow conditionally stable regime is that substantial strain can accumulate in the weak materials without complete relaxation by creep.

[11] The conditionally stable region should be laterally heterogeneous along the thrust contact zone, as a variety of features and mechanisms can produce isolated asperities embedded in weaker sedimentary materials. These include subducted seamounts, ridges, and horst and graben faults on the subducting plate, all of which can give rise to roughness on the thrust fault. Tanioka et al. [1996] suggest that roughness created by horst and graben structures on the subducting Pacific plate influenced the generation of the 1896 tsunami earthquake in Japan. In addition, variations in subducted sediment volumes, sediment composition, and metamorphic processes can influence asperity distribution. Pacheco et al. [1993] postulate coupling variations can arise from permeability changes in the subduction zone. For example, subduction of low permeability materials may cause an increase in pore fluid pressure and decrease in normal stress, keeping a region in the stable or conditionally stable regime to greater depths.

[12] The proposed mechanism for generation of both large tsunami earthquakes and smaller long duration earthquakes with similar scaled features is rupture within these frictional conditions on the interface. The heterogeneous size distribution of asperities controls the size of earthquakes. Large tsunami earthquakes likely represent the breaking of one or several large asperities which triggers rupture into the conditionally stable region over a long narrow strip at shallow depth. Large slip in the shallow strip leads to large sea-floor displacement and strong tsunami excitation. This large shallow slip may also lead

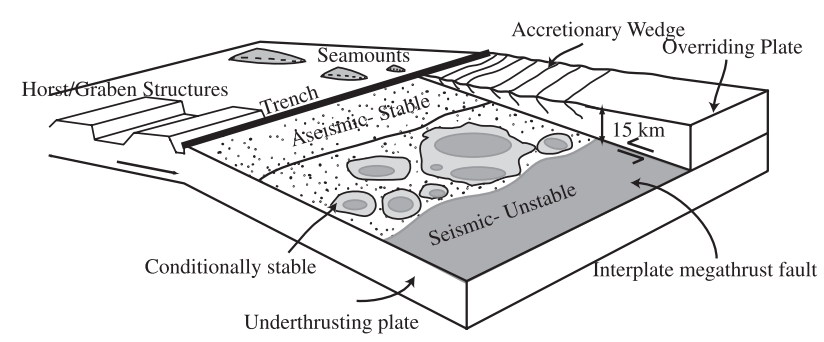

Figure 3. Cartoon illustrating frictional conditions of the subduction thrust fault plane. Individual unstable sliding contact areas (dark gray) can provide the nucleation sites for rupture in the shallow subduction zone environment, which is typically a stable (stippled) or conditionally stable (light gray) frictional region. 
to additional uplift of trench wedge sediments, which could also aid in tsunami generation [Seno, 2000; Tanioka and Seno, 2001]. Low rigidity of material in the source volume causes slow rupture velocity and a decrease of seismic amplitudes as the waves propagate outward into surrounding rock of higher rigidity (the expected decrease is roughly proportional to the increase in rigidity). Seismic source strength estimates based on uniform crustal structures with standard rigidity values underestimate slip at the source, making the tsunami excitation appear anomalous relative to the seismic moment [Satake and Tanioka, 1999]. Smaller shallow earthquakes rupture smaller asperities and many trigger slip in the surrounding conditionally stable region with comparable scaling to larger events. Deeper along the interplate fault $(>10-15 \mathrm{~km})$, the conditionally stable materials transition into the unstable slip regime, and rupture velocities and source durations assume typical hard rock values, with tsunami excitation consistent with seismic estimates based on standard models.

[13] This scenario, which places an emphasis on universal depth dependence rather than localized special circumstances, suggests that large, tsunami earthquakes can occur in any subduction zone where a shallow conditionally stable zone containing large asperities exists. Five of the 14 subduction zones in our global dataset have produced both large tsunami earthquakes and smaller long duration events. The remaining nine regions have all experienced smaller long duration events, but have not historically produced a large tsunami earthquake. There are two possibilities, either these subduction zones lack large asperities embedded in regions of conditional stability, or the historical earthquake catalog is simply not long enough to have captured failure of the shallow region due to the low rate of seismicity at very shallow depths. The former explanation is unlikely given the many mechanisms that may produce conditionally stable regimes in the subduction zone environment, suggesting that all of the global subduction zones are capable of producing large shallow earthquakes with large tsunamis, although given only six in the past century, with low frequency.

[14] Acknowledgments. Earthquake data were provided by IRIS DMC. We thank Larry Ruffand Roland von Huene for comments on early versions of the manuscript. We also thank the 2 anonymous reviewers for useful improvements to the manuscript. Supported by NSF.

\section{References}

Abercrombie, R. E., M. Antolik, K. Felzer, and G. Ekström, The 1994 Java tsunami earthquake: Slip over a subducting seamount, J. Geophys. Res., 106, 6595-6607, 2001.

Bilek, S. L., and T. Lay, Rigidity variations with depth along interplate megathrust faults in subduction zones, Nature, 400, 443-446, 1999.

Bilek, S. L., and T. Lay, Depth dependent rupture properties incircumPacific subduction zones, in GeoComplexity and the Physics of Earthquakes, edited by J. B. Rundle, D. L. Turcotte, and W. Klein, pp. $165-$ $186,2000$.

Campus, P., and S. Das, Comparison of the rupture and radiation characteristics of intermediate and deep earthquakes, J. Geophys. Res., 105, $6177-6189,2000$.
Houston, H., H. M. Benz, and J. E. Vidale, Time functions of deep earthquakes from broadband and short period stacks, J. Geophys. Res., 103, 29,895-29,913, 1998

Ihmlé, P. F., Frequency-dependent relocation of the 1992 Nicaragua slow earthquake: An empirical Green's function approach, Geophys. J. Int., 127, 75-85, 1996.

Ihmlé, P. F., J. M. Gomez, P. Heinrich, and S. Guibourg, The 1996 Peru tsunamigenic earthquake: Broadband source process, Geophys. Res. Lett., 25, 2691-2694, 1998.

Johnson, J. M., and K. Satake, Estimation of seismic moment and slip distribution of the April 1, 1946, Aleutian tsunami earthquake, J. Geophys. Res., 102, 11,765-11,774, 1997.

Kanamori, H., Mechanism of tsunami earthquakes, Phys. Earth Planet. Int., 6, 246-259, 1972.

Kanamori, H., and D. L. Anderson, Theoretical basis of some empirical relations in seismology, Bull. Seismo. Soc. Am., 65, 1073-1095, 1975.

Kanamori, H., and M. Kikuchi, The 1992 Nicaragua earthquake: A slow tsunami earthquake associated with subducted sediments, Nature, 361, 714-716, 1993.

Newman, A. V., and E. A. Okal, Teleseismic estimates of radiated seismic energy: The $\mathrm{E} / \mathrm{M}_{o}$ discriminant for tsunami earthquakes, J. Geophys. Res., 103, 26,885-26,898, 1998.

Okal, E. A., Seismic parameters controlling far-field tsunami amplitudes: A review, Nat. Haz., 1, 67-96, 1988.

Pacheco, J. F., L. R. Sykes, and C. H. Scholz, Nature of seismic coupling along simple plate boundaries of the subduction type, J. Geophys. Res., 98, 14,133-14,159, 1993.

Pelayo, A. M., and D. A. Wiens, The November 20, 1960 Peru tsunami earthquake: Source mechanism of a slow event, Geophys. Res. Lett., 17, 661-664, 1990.

Pelayo, A. M., and D. A. Wiens, Tsunami earthquakes: Slow thrust-faulting events in the accretionary wedge, J. Geophys. Res., 97, 15,321-15,337, 1992.

Polet, J., and H. Kanamori, Shallow subduction zone earthquakes and their tsunamigenic potential, Geophys. J. Int., 142, 684-702, 2000.

Ruff, L. J., and H. Kanamori, The rupture process and asperity distribution of three great earthquakes from long period diffracted $P$-waves, Phys. Earth Planet. Int., 31, 202-230, 1983.

Ruff, L. J., Multi-trace deconvolution with unknown trace scale factors: Omnilinear inversion of $P$ and $S$ waves for source time functions, Geophys. Res. Lett., 16, 1043-1046, 1989.

Ruff, L. J., and A. D. Miller, Rupture process of large earthquakes in the northern Mexico subduction zone, Pure Appl. Geophys., 142, 101-171, 1994.

Satake, K., Mechanism of the 1992 Nicaragua tsunami earthquake, Geophys. Res. Lett., 21, 2519-2522, 1994.

Satake, K., and Y. Tanioka, Sources of tsunami and tsunamigenic earthquakes in subduction zones, Pure Appl. Geophys., 154, 467-483, 1999.

Scholz, C., The mechanics of earthquakes and faulting, (Cambridge Univ. Press, 1990).

Scholz, C. H., Earthquakes and friction laws, Nature, 391, 37-42, 1998.

Seno, T., The 21 September, 1999 Chi-Chi earthquake in Taiwan: Implications for tsunami earthquakes, Terr. Atmos. Ocean Sci., 11, 701-708, 2000 .

Tanioka, Y., and K. Satake, Fault parameters of the 1896 Sanriku tsunami earthquake estimated from tsunami numerical modeling, Geophys. Res. Lett., 23, 1549-1552, 1996.

Tanioka, Y., and T. Seno, Sediment effect on tsunami generation of the 1896 Sanriku tsunami earthquake, Geophys. Res. Lett., 28, 3389-3392, 2001.

Tichelaar, B. W., and L. J. Ruff, Seismic coupling along the Chilean subduction zone, J. Geophys. Res., 96, 11,997-12,022, 1991.

Velasco, A. A., C. J. Ammon, T. Lay, and J. Zhang, Imaging a slow bilateral rupture with broadband seismic waves: The September 2, 1992 Nicaraguan tsunami earthquake, Geophys. Res. Lett., 21, 2629-2632, 1994.

S. L. Bilek, Department of Geological Sciences, University of Michigan, Ann Arbor, MI 48109, USA. (sbilek@umich.edu)

T. Lay, Institute of Geophysics and Planetary Physics and Earth Sciences Department, University of California, Santa Cruz, 1156 High Street, Santa Cruz, CA 95064, USA. (thorne@es.ucsc.edu) 